\title{
The thermal structure of the anoxic trough in Lake Untersee, Antarctica
}

\author{
JAMES BEVINGTON ${ }^{1,2}$, CHRISTOPHER P. MCKAY ${ }^{2}$, ALFONSO DAVILA ${ }^{2}$, IAN HAWES $^{3}$, \\ YUKIKO TANABE ${ }^{4}$ and DALE T. ANDERSEN ${ }^{5}$ \\ ${ }^{1}$ International Space University, Strasbourg, France \\ ${ }^{2}$ Space Science Division, NASA Ames Research Center, Moffett Field, CA, USA \\ ${ }^{3}$ The University of Waikato Tauranga, New Zealand \\ ${ }^{4}$ National Institute of Polar Research, Tokyo, Japan \\ ${ }^{5}$ Carl Sagan Center for the Study of Life in the Universe, SETI Institute, Mountain View, CA, USA \\ dandersen@seti.org
}

\begin{abstract}
Lake Untersee is a perennially ice-covered Antarctic lake that consists of two basins. The deepest basin, next to the Anuchin Glacier is aerobic to its maximum depth of $160 \mathrm{~m}$. The shallower basin has a maximum depth of $100 \mathrm{~m}$, is anoxic below $80 \mathrm{~m}$, and is shielded from convective currents. The thermal profile in the anoxic basin is unusual in that the water temperature below $50 \mathrm{~m}$ is constant at $4^{\circ} \mathrm{C}$ but rises to $5^{\circ} \mathrm{C}$ between $70 \mathrm{~m}$ and $80 \mathrm{~m}$ depth, then drops to $3.7^{\circ} \mathrm{C}$ at the bottom. Field measurements were used to conduct a thermal and stability analysis of the anoxic basin. The shape of the thermal maximum implies two discrete locations of energy input, one of $0.11 \mathrm{~W} \mathrm{~m}^{-2}$ at $71 \mathrm{~m}$ depth and one of $0.06 \mathrm{~W} \mathrm{~m}^{-2}$ at $80 \mathrm{~m}$ depth. Heat from microbial activity cannot account for the required amount of energy at either depth. Instead, absorption of solar radiation due to an increase in water opacity at these depths can account for the required energy input. Hence, while microbial metabolism is not an important source of heat, biomass increases opacity in the water column resulting in greater absorption of sunlight.
\end{abstract}

Received 21 February 2018, accepted 05 July 2018

Key words: climate change, Dronning Maud Land, lake, solar heating

\section{Introduction}

Lake Untersee, an oligotrophic, perennially ice-covered freshwater lake in central Dronning Maud Land in East Antarctica, exhibits an unusual thermal structure (Wand et al. 1997). The lake consists of two basins, the northern basin with a maximum reported depth of $169 \mathrm{~m}$ is in contact with a glacial wall and is convectively mixed to the bottom (Steel et al. 2015), and a second basin to the south is an "anoxic trough", which is partially shielded from the currents in the main water column (Fig. 1). The lake is ice-sealed, meaning that water does not enter the lake from streams. Instead, melt from the Anuchin Glacier is the primary source of water.

An anomalous temperature structure in the anoxic trough was first documented in 1987 (Wand et al. 1997), and the same anomaly has been observed since then (Wand et al. 2006, Andersen et al. 2011, Steel et al. 2015). The temperature profile in the anoxic basin is constant at $0.5^{\circ} \mathrm{C}$ to $50 \mathrm{~m}$, indicating the depth where shielding from the main basin occurs. At $50 \mathrm{~m}$ the temperature increases sharply to $\sim 4^{\circ} \mathrm{C}$, roughly the density maximum of freshwater. Between $50 \mathrm{~m}$ and $\sim 65 \mathrm{~m}$ the temperature is constant, implying a convective cell. From $\sim 65 \mathrm{~m}$, temperature increases linearly to $\sim 5^{\circ} \mathrm{C}$ at $\sim 70 \mathrm{~m}$ where it remains constant to $\sim 80 \mathrm{~m}$. Below $80 \mathrm{~m}$ temperature decreases linearly to $\sim 3.7^{\circ} \mathrm{C}$ at $100 \mathrm{~m}$ depth (Wand et al. 1997) (Fig. 2).

Inverse thermal profiles have been reported in icecovered lakes in the McMurdo Dry Valleys (Wilson \& Wellman 1962, Hoare et al. 1964, 1965, Shirtcliffe 1964, Bell 1967). These thermal profiles have been explained by radiative heating through the lake, and by an increase in salinity with depth, which stabilizes the water column (Wilson \& Wellman 1962, Shirtcliffe 1964), even in lakes with very low salinity (Bell 1967). Obryk et al. (2016) demonstrated the importance of solar heating in determining the thermal structure of the perennially icecovered Lake Fryxell and west lobe of Lake Bonny. In the McMurdo Dry Valleys lakes, temperature plays a minor role in water column stability compared to salinity because temperature ranges are small and they generally overlap with the temperature of maximum density near $4^{\circ} \mathrm{C}$ (Spigel \& Priscu 1998). However, water in Lake 


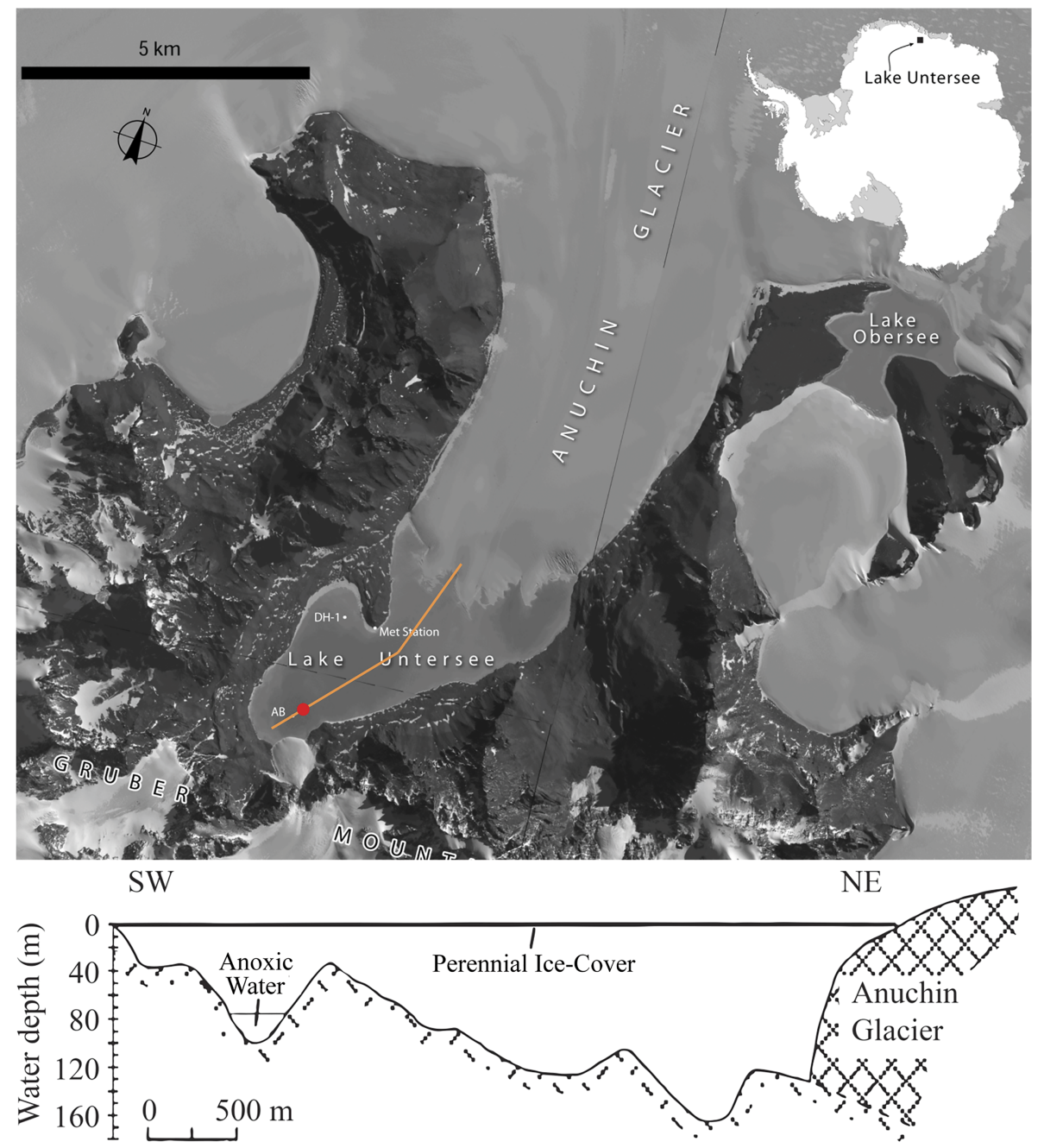

Fig. 1. Satellite imagery and cross-section of Lake Untersee. The cross-section follows the orange line marked on the satellite image. The northern basin is bounded by the Anuchin Glacier which provides a mixing force and thermal sink holding the main lake body near $0^{\circ} \mathrm{C}$. The geometry of the anoxic trough to the southwest end of the cross-section shields the water column from mixing currents in the main body which allows anoxic conditions to persist. The sampling location is marked with a red point. Satellite imagery copyright DigitalGlobe, Inc., provided by NGA Commercial Imagery Program. Profile based on Wand et al. 2006.

Untersee is fresh, so salinity is less efficient at stabilizing the water column. In addition, the maximum temperature $\left(5^{\circ} \mathrm{C}\right)$ is above the density maximum of water $\left(4^{\circ} \mathrm{C}\right)$.

Wand et al. (1997, 2006) suggested that the thermal increase of $1^{\circ} \mathrm{C}$ between $70 \mathrm{~m}$ and $80 \mathrm{~m}$ depth might be explained by microbial metabolism associated with $\mathrm{CH}_{4}$ oxidation, sulfate reduction, and possibly sulfide oxidation, analogous to reports of microbial heating in marine environments (Schwabe \& Herbert 2004) and compost heaps and landfills (Pirt 1978). If confirmed, the presence of microbially heated layers in Lake Untersee would be a first in Antarctic limnology.

The aim of this study was to investigate the water column stability and possible thermal sources to explain the unusual temperature profile between $70 \mathrm{~m}$ and $80 \mathrm{~m}$ depth in the anoxic trough of Lake Untersee. Using field measurements, heating due to absorption of solar insolation through the water column was compared to the theoretical heating derived from chemical energy generation due to aerobic methane oxidation.

\section{Methods}

\section{Site description}

Lake Untersee covers an area of $11.4 \mathrm{~km}^{2}$ (Loopmann et al. 1988) making it one of the largest lakes in East Antarctica. It has an elevation of $563 \mathrm{~m}$ (Andersen et al. 2011) and average ice thickness of $3 \mathrm{~m}$ (Wand et al. 1997). Detailed bathymetry of the lake by 


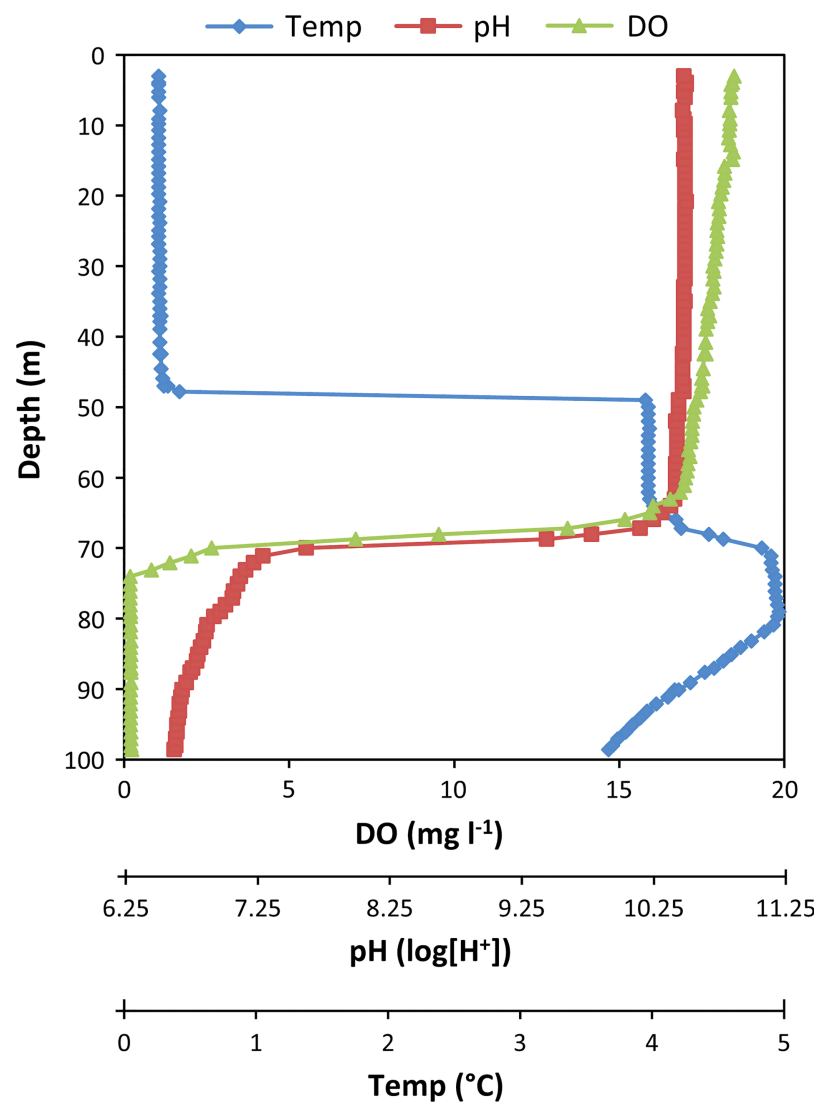

Fig. 2. Profiles of dissolved oxygen, $\mathrm{pH}$ and temperature from November 2011. The top portion is well mixed by glacially driven currents above the ridge at $\sim 50 \mathrm{~m}$. The thermocline at $50 \mathrm{~m}$ is well above the oxycline at $68 \mathrm{~m}$ where $\mathrm{pH}$ and dissolved oxygen (DO) have sharp decreases. Between these depths, the water column is uniform. From $70-74 \mathrm{~m}$ is a suboxic region which gives way to anoxic conditions below.

Wand et al. (1996) revealed that the lake has a large and deep basin in contact with the Anuchin Glacier on the northern edge, which is separated by a narrow sill from the southern end where there is a relatively narrow basin that is not in contact with the shore or with any glaciers (Fig. 1).

The water column in the large basin is well mixed with nearly isothermal temperature profiles and has supersaturated, approximately uniform, concentrations of dissolved oxygen to depths of $169 \mathrm{~m}$. Steel et al. (2015) have shown that the presence of the ice wall of the Anuchin Glacier acts as a heat sink that prevents thermal stabilization of the main basin: water in contact with the glacier wall is cooled below $4^{\circ} \mathrm{C}$ and as a result is buoyant and rises. The currents driven by this process effectively mix the water column. However, in the smaller southern basin, there is no deep ice to drive convection and the deep and relatively narrow topography blocks these currents, creating stagnant conditions with anoxia developing at depth (Steel et al. 2015).

\section{Water column measurements}

Four profiles of temperature, depth, conductivity, dissolved oxygen, $\mathrm{pH}$ and fluorescence of chlorophyll $a$ (chl $a$ ) were obtained using a Hydrolab DS5 multiparameter water quality sonde (OTT Hydromet, 5600 Lindbergh Drive, Loveland, CO 80539, USA) connected to a field-portable computer. The sonde was factory calibrated four weeks prior to taking each profile, and $\mathrm{pH}$ and dissolved oxygen were calibrated in the field before each set of measurements. A $25 \mathrm{~cm}$ diameter hole was drilled through the ice to access the water column. Profiles of the water column were obtained on 22 November 2008, 28 November 2011, 5 December 2011 and 1 December 2015. The measurement uncertainty between profiles or casts (instrument uncertainties) was $\pm 0.1^{\circ} \mathrm{C}$ for temperature, $\pm 1 \%$ for conductivity, and $\pm 0.05 \mathrm{~m}$ for depth, and it was a factor of two lower for measurements made in the same profile (relative uncertainties from point to point with a cast). The sonde was lowered or raised in $1 \mathrm{~m}$ increments and held at each for several measurements. An additional profile of temperature, depth and conductivity was obtained using a RBR concerto (RBR Ltd. 95 Hines Road, Ottawa, ON K2K 2M5 Canada) on 20 November 2016. The sonde was lowered at a rate of $0.13 \mathrm{~m} \mathrm{~s}^{-1}$ to $50 \mathrm{~m}, 0.07 \mathrm{~m} \mathrm{~s}^{-1}$ to the bottom, then raised at a rate of $0.19 \mathrm{~m} \mathrm{~s}^{-1}$ and had a sampling rate of 3 samples s $^{-1}$. In the analysis, the 2016 profile was corrected for atmospheric pressure and low salinity in post processing. There is very little variability in the profiles spanning eight years.

\section{Water column stability}

Water density profiles were computed from temperature and conductivity profiles where points were binned into $1 \mathrm{~m}$ depth brackets (Fig. 3). Comparing repeated scans and upward and downward scans showed that the sampling method was slow enough to prevent hysteresis or memory effects, well below a few percent. In addition, binning minimizes hysteresis effects in the 2016 profile where the sonde was not rested between measurements. The UNESCO formula was used to convert conductivity to total dissolved solids and density (Chen \& Millero 1977, Lewis 1980, Millero \& Poisson 1981, Fofonoff \& Millard 1983, Chen \& Millero 1986, Spigel \& Priscu 1996, 1998, Boehrer et al. 2010). The UNESCO formula is based on seawater, which has a different composition to the water in Lake Untersee. To correct for any errors in density estimation due to this compositional difference, density was directly computed at several depths using direct measurements of the chemical composition of the water (Table 1, Andersen et al. 2011) and the method of Boehrer et al. (2010). Data from $95 \mathrm{~m}$ depth and below were not used because the density here was calculated to 

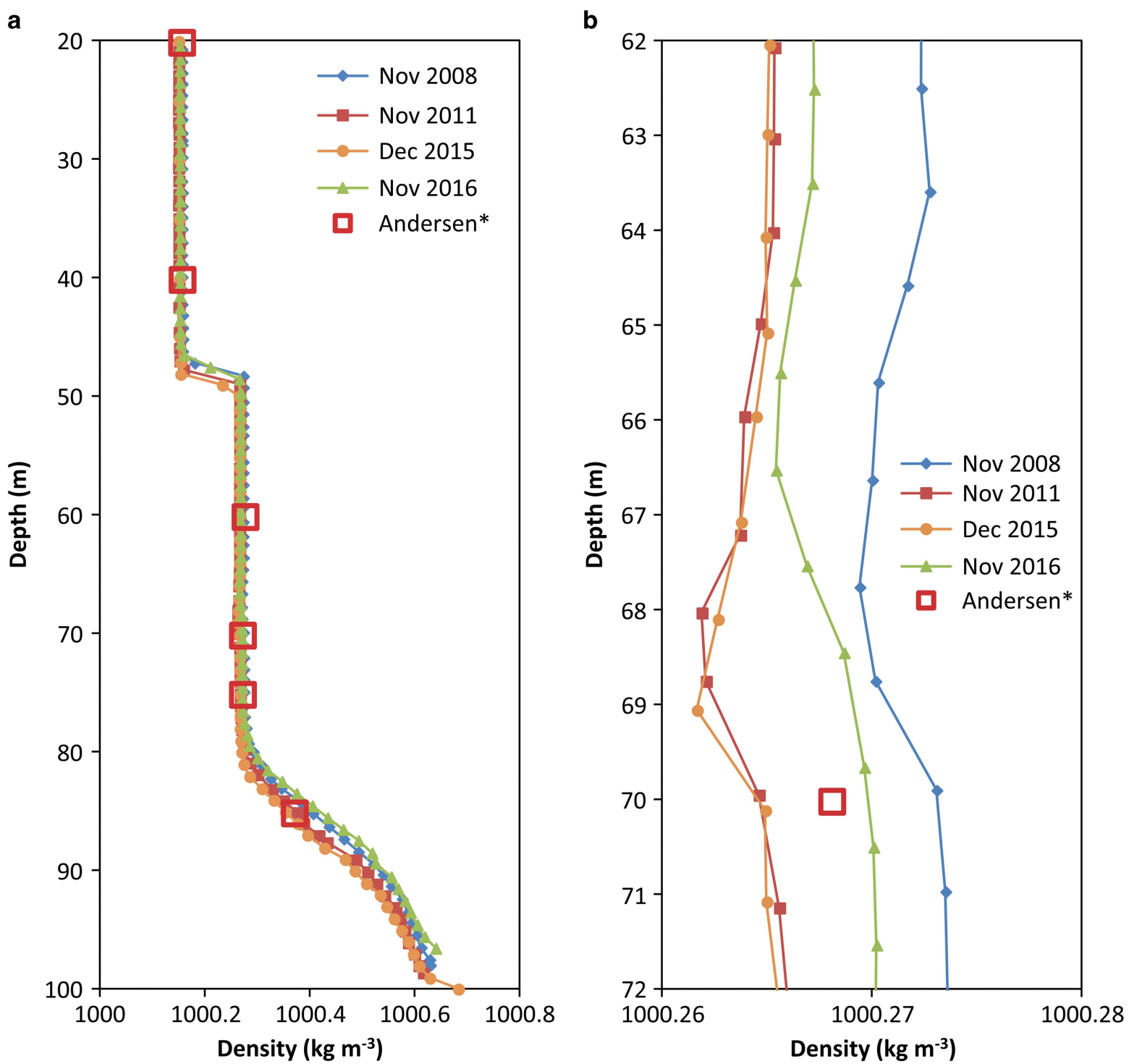

Fig. 3. Density profiles calculated using the UNESCO method shifted to match density calculated using the method of Boehrer $e t$ al. (2010) and data from table 1, Andersen et al. (2011). a. The zone above $50 \mathrm{~m}$ is connected to the main lake body which is well mixed. The middle zone from 50-68 m which sits between the thermocline and oxycline (chemocline) is a slightly mixed zone. From $68-80 \mathrm{~m}$ the column in neutrally stable and below $80 \mathrm{~m}$, stable. b. There is a slight decrease in density from $64-69 \mathrm{~m}$.

be significantly less than the layer above it. The density profiles computed from the sonde data with the UNESCO formula were then adjusted to agree with the directly computed values. To reach agreement, all profiles were shifted by the addition of a constant $0.034 \mathrm{~kg} \mathrm{~m}^{-3}$. This offset had no impact on stability analysis, which depends only on relative densities.

Pressure effects on density were not considered because they do not contribute to the stability of stratification (Boehrer et al. 2010). Stability is determined as the difference between the actual density gradient and the gradient in density that would result from an adiabatic lapse rate in density with pressure and temperature.
Consequently, in this paper (as in Boehrer et al. 2010) the density was computed with respect to atmospheric pressure, and stability was determined simply as an increase in density with depth.

\section{Thermal analysis}

The thermal analysis focused on the region from $70-100 \mathrm{~m}$ depth, which was assumed to be fully diffusive with no significant convective transport of heat. Mixing would stop the thermal structure from forming; thus, convection must be a minor component of heat transfer, if it is a factor at all. The thermal gradient was 
approximated by fitting regression lines to subsections of the measured temperature profiles. These regression lines facilitated numerical calculations by smoothing over noise in the data. The product of temperature gradient and the thermal conductivity coefficient (given as $0.577 \mathrm{~W} \mathrm{~m}^{-1} \mathrm{~K}^{-1}$ by Ramires et al. 1995) was used to estimate the thermal flux, and a change in gradient was taken to indicate a location of heat gain or loss.

$$
\mathrm{Q}=\mathrm{k}(\mathrm{dT} / \mathrm{dz})_{\text {upper }}-\mathrm{k}(\mathrm{dT} / \mathrm{dz})_{\text {lower }},
$$

where $\mathrm{Q}$ is the heat source, $\mathrm{k}$ is the thermal conductivity, $\mathrm{T}$ is the temperature, $\mathrm{z}$ is depth decreasing downward, and the subscripts "upper" and "lower" refer to segments defined with respect to the location of the heat source. Physically, this is equivalent to summing the fluxes out of a point layer which must be offset by energy input at that layer. For the lower and middle segments all points were included in the analysis, but the upper segment contained artefacts from a convective boundary (Fig. $3 \mathrm{~b}$ ), making determination of the slope of the segment difficult. Thus, the representative lines for the upper segment included only the deepest few points, which were most clearly in the diffusive regime. Fluxes derived from each of the five measured temperature profiles were then averaged.

\section{Chemical and biological heat model}

The methane profile reported in Wand et al. (2006) was used to estimate the possible contribution of metabolic reactions to the water temperature profiles. In particular, Wand et al. (2006) noted that the methane profile is separated into two regions. From the bottom to $80 \mathrm{~m}$ depth the methane concentration was linear with depth, indicating constant diffusion upward without significant loss. From $80 \mathrm{~m}$ depth upward to $70 \mathrm{~m}$ depth the methane concentration continued to decrease but at a decreasing rate, indicating diffusion upward with loss of methane. Fitting a line to the mostly linear segment from $80 \mathrm{~m}$ depth to the bottom provided an estimate of methane flux (slope multiplied by diffusion coefficient) into the consumption zone. To estimate an upper bound on chemical energy generation from methane consumption it was assumed that all consumption was due to oxidation by $\mathrm{O}_{2}$ to $\mathrm{CO}_{2}$ of all methane produced. The flux of methane was determined based on its diffusion coefficient in water of $9.8 \times 10^{-6} \mathrm{~cm}^{2} \mathrm{~s}^{-1}$ at $0.85^{\circ} \mathrm{C}$ (Yaws 2009). The energy released by the reaction of $\mathrm{CH}_{4}$ with $\mathrm{O}_{2}$ was taken as $890 \mathrm{~kJ} \mathrm{~mol}^{-1}$ (Weast 1976).

\section{Radiative energy heat model}

The gradient of the photosynthetically active radiation (PAR) profile was used as the basis for the radiative energy model because longer wavelengths are rapidly absorbed by ice and the first few metres of water (McKay et al. 1994, Warren \& Brandt 2008). A single profile of radiation in the PAR range $(400-700 \mathrm{~nm})$ was measured using a LI-193 spherical quantum sensor (LI-COR, Lincoln, NE 68504, USA) lowered through a hole drilled in the ice cover on 18 November 2011. Measurements were recorded at $5 \mathrm{~m}$ increments until $75 \mathrm{~m}$ where $1 \mathrm{~m}$ increments were used. To normalize the measurements in the water column for changing surface conditions, surface incident radiation was measured simultaneously using a LI-190 cosine corrected sensor (LI-COR, Lincoln, NE 68504, USA) and the percentage of incidence was calculated and used to normalize the underwater measurements. The measured PAR profile represented the proportion of photons in the PAR range reaching a particular depth, which was independent of the surface radiation on the day it was measured. To compute the mean annual radiation at depth, the profile was scaled such that the light level just below the ice at the top of the water column was $2.6 \mathrm{~W} \mathrm{~m}^{-2}$, is the estimate of the mean annual irradiance as determined from measured surface irradiance, PAR transmissivity, albedo of the ice cover and the theoretical absorption properties of ice over the solar spectrum (Steele et al. 2015). It was assumed that photons lost in the water column were completely converted to heat (i.e. negligible conversion to biological or chemical energy). The energy input at each depth was estimated by calculating the slope of the PAR profile.

\section{Results}

\section{Water column stability}

The temperature, oxygen and $\mathrm{pH}$ profiles (Fig. 2), and the computed density profile (Fig. 3), confirmed the existence of four temperature zones, defined below, in the water column of the anoxic trough. This structure was also reflected in the conductivity profiles (Fig. 4).

The water column was well mixed above the thermocline at $50 \mathrm{~m}$ depth. From $50-80 \mathrm{~m}$ depth, water density was uniform but higher than the density in the main lake body (Fig. 3). The slope of the density profile indicated that the water column was either mixed or neutral (not mixing but not stable). The chemocline/ oxycline was observed within this region ( $68 \mathrm{~m}$ depth), which suggests that the water column from $50-68 \mathrm{~m}$ depth does not mix with the water column from 68-80 m depth. Below $80 \mathrm{~m}$ depth, water density increased to the bottom of the lake. Repeated measurements across eight years revealed identical profiles, suggesting that this portion of the water column must be fully diffusive and stable. A thermal maximum of $5^{\circ} \mathrm{C}$ occurred $10 \mathrm{~m}$ below a column of water at $4^{\circ} \mathrm{C}$. This thermal rise could cause instability through a density decrease of $\sim 0.01 \mathrm{~kg} \mathrm{~m}^{-3}$, but 


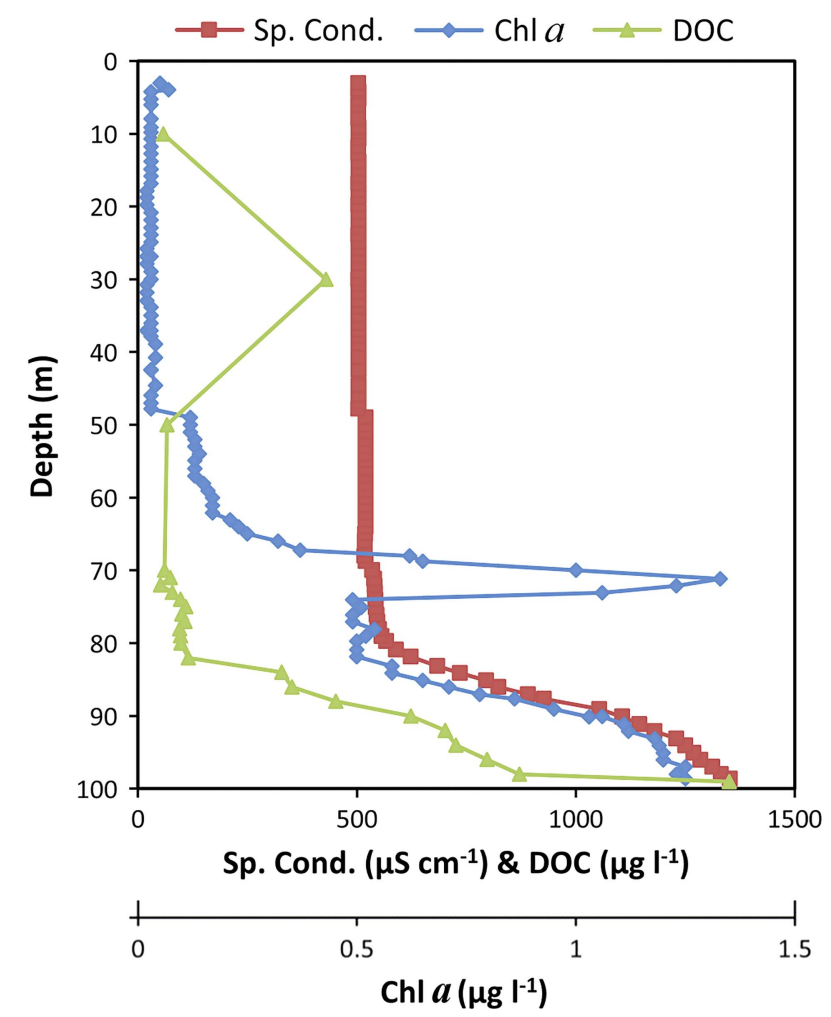

Fig. 4. Profiles of chlorophyll $a(\mathrm{chl} a)$, specific conductivity at $25^{\circ} \mathrm{C}$ (Sp. Cond.) and dissolved organic carbon (DOC) (Wand et al. 2006) in the anoxic trough. The chl $a$ profile shows a peak at $71.1 \mathrm{~m}$ corresponding to a layer of photosynthetic organisms just at the oxycline. The increase in chl $a$ below $80 \mathrm{~m}$ may be an artefact of the organic molecules in the water. The conductivity profile shows an increase at $50 \mathrm{~m}$, decrease at $68 \mathrm{~m}$, and rapid increase below $80 \mathrm{~m}$ corresponding very closely to the density profile. The dissolved organic carbon profile represents organic molecules in the water column.

a slight increase of about $0.012 \mathrm{~kg} \mathrm{~m}^{-3}$ observed in organic matter in the same zone (Fig. 4) should be sufficient to just stabilize the water column.

There was evidence of a slight unstable slope in density around $65 \mathrm{~m}$ depth (Fig. 3b). The persistence of this feature in profiles taken many years apart suggests that it cannot be attributed to sensor noise. When density inversions are very small, conduction is the mode of heat transfer (e.g. Heitz \& Westwater 1971). To provide a numerical estimate of the strength of convection, the Rayleigh number $\left(R_{a}\right)$ was computed:

$$
\mathrm{R}_{\mathrm{a}}=\alpha \Delta \mathrm{TgH}^{3} / \nu \mathrm{K},
$$

where $\alpha$ is the thermal expansion coefficient, $g$ is gravity, $\Delta \mathrm{T}$, is the temperature difference across the layer of thickness $\mathrm{H}, v$ is the kinematic viscosity and $K$ is the thermal diffusivity. Noting that $\alpha \Delta \mathrm{T}$ is the fractional change in specific volume, $\mathrm{v}$, between the top and bottom of the layer, one can express this in terms of the density, $\rho$, such that

$$
\alpha \Delta \mathrm{T}=\Delta \mathrm{v} / \mathrm{v}=\rho \Delta\{1 / \rho\} \approx \Delta \rho / \rho .
$$

At $4{ }^{\circ} \mathrm{C}$, the kinematic viscosity of water is $1.6 \times 10^{-6} \mathrm{~m}^{2} \mathrm{~s}^{-1}$ and the thermal diffusivity is $1.4 \times 10^{-7} \mathrm{~m}^{2} \mathrm{~s}^{-1}$. From Fig. $3 \mathrm{~b}$, density values varied by about $0.002 \mathrm{~kg} \mathrm{~m}^{-3}$ (hence $\Delta \rho / \rho \sim 2 \times 10^{-6}$ ) over a range of $\sim 1 \mathrm{~m}$. Equations (1) and (2) yielded $\mathrm{R}_{\mathrm{a}} \sim 10^{8}$, five orders of magnitude higher than the limit for heat transport due exclusively to molecular heat diffusion in horizontal layers with horizontal length scale much larger than the vertical length scale (Heitz \& Westwater 1971). $R_{a}$ also exceeded the limit for transition from laminar natural convection to turbulent natural convection $\left(10^{5}-10^{6}\right)$. Our analysis points to a small turbulent convective layer at $\sim 65 \mathrm{~m}$ depth that is persistent over many years but may vary in a location by a few metres.

\section{Thermal analysis}

The temperature profiles from $70-100 \mathrm{~m}$ depth showed a linear increase followed by a relatively flat plateau at the maximum temperature $\left(5^{\circ} \mathrm{C}\right)$ and then a linear decrease (Fig. 5). Given the shape of the temperature maximum, our thermal analysis commenced by fitting three linear segments to the temperature maximum. For most segments, regression lines fitted their respective segments with an $R^{2}$ value greater than 0.9 . Values of $R^{2}$ less than 0.9 were only found in middle segments of December 2011, December 2015 and November 2016. Methodically removing potential visual outliers from December 2011 revealed that the regression line was not strongly affected by these points as the slope and intercept values did not change significantly. The weakness of $R^{2}$ as an evaluation of fit quality is acknowledged but given the small number of data points more complex estimators were not practical.

Results from all years were very similar to each other apart from the heat flux leaving the upper portion of the temperature maximum. These results are presented in Table I, which shows that the average upward heat flux from the top layer was $0.112 \mathrm{~W} \mathrm{~m}^{-2}$ and the range for the top was $0.078-0.139 \mathrm{~W} \mathrm{~m}^{-2}$ - a greater range than that for the other layers (Table I) - and reflects both the numerical resolution of the dataset and the variable physical processes. This upper segment (between $\sim 65 \mathrm{~m}$ and $\sim 70 \mathrm{~m}$ ) was affected by the slight instability at $\sim 65 \mathrm{~m}$ depth (Fig. 3b), which resulted in a small convection zone. This convective boundary had an impact on the heat diffused from the layer and might slightly fluctuate in time. The variable magnitude of this upward flux also had a noticeable impact on the total energy requirement because the majority of the energy leaving the temperature maximum system did so from the top. To 
a

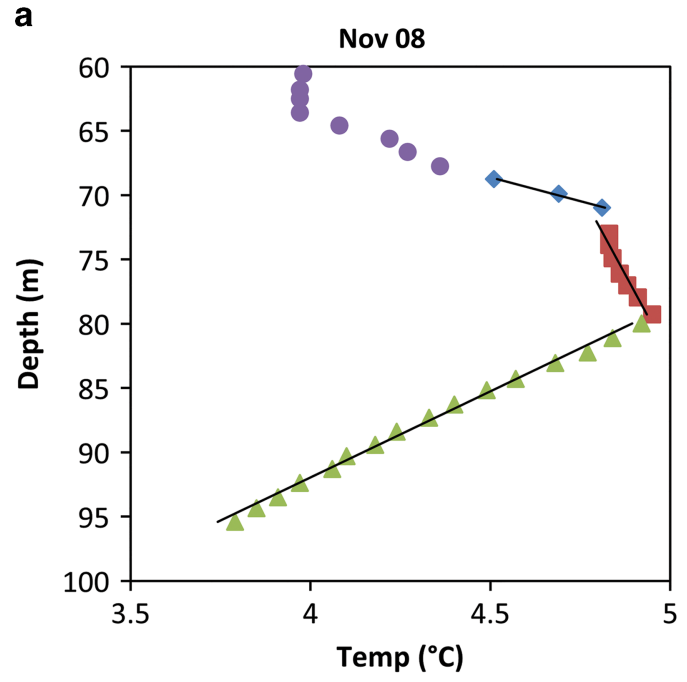

C

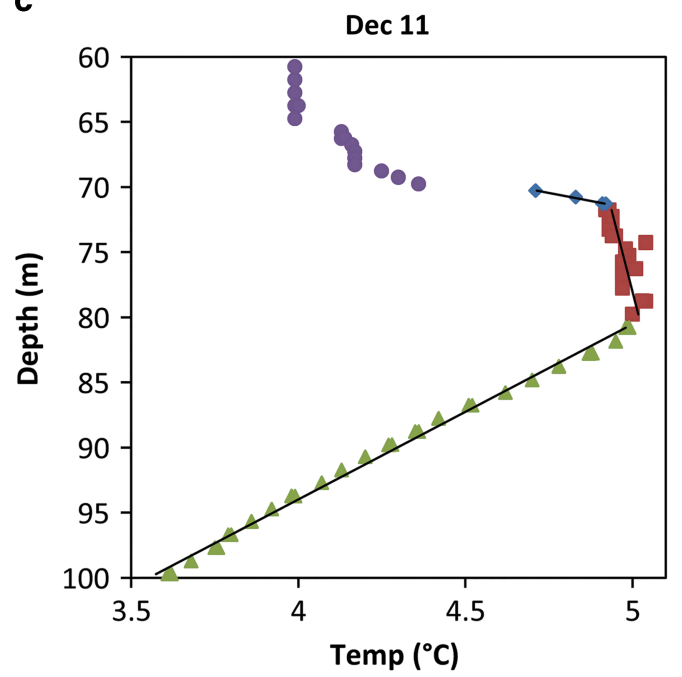

e

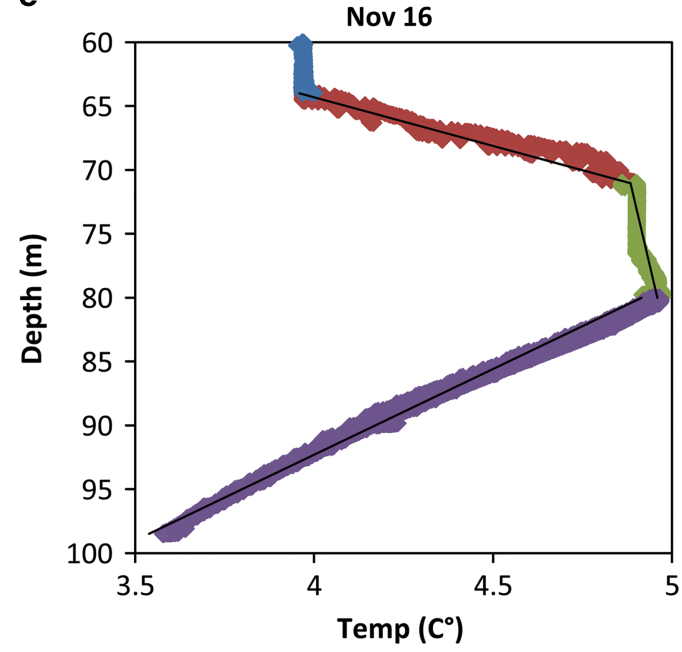

b

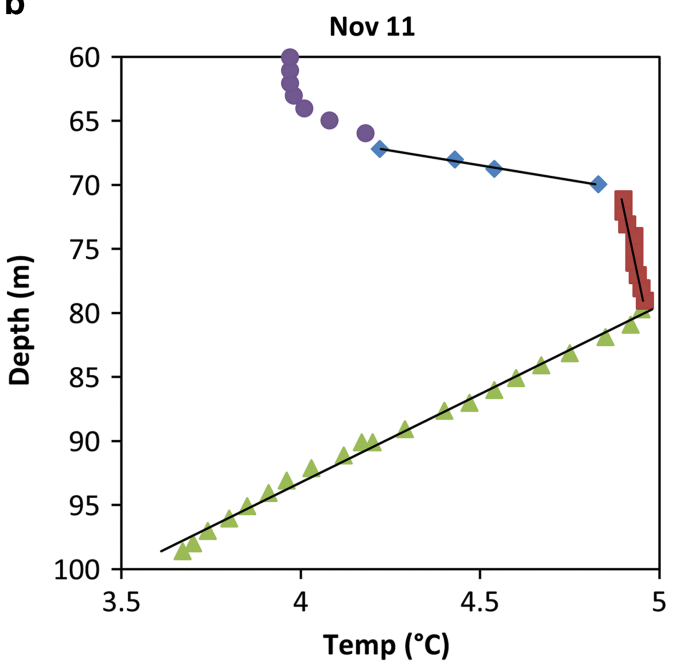

d

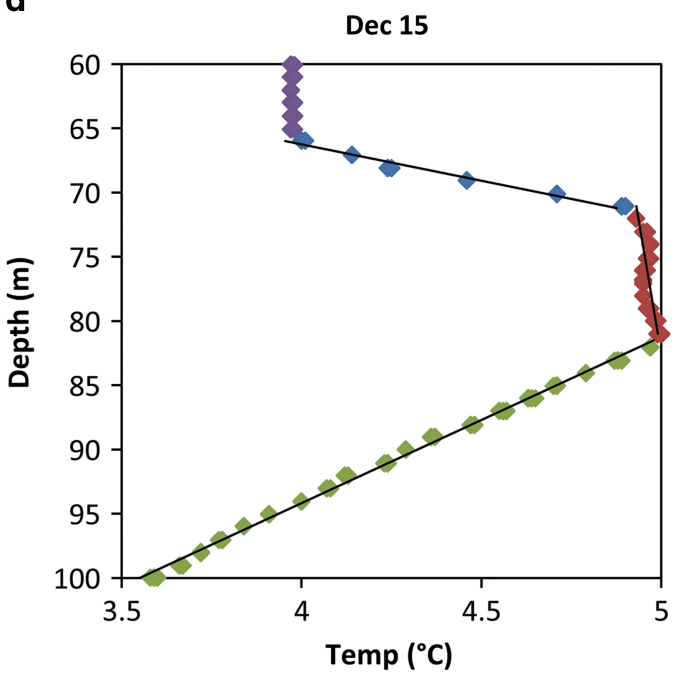

Fig. 5. Temperature profiles and fitted lines from five years. The uppermost points represent the convective transition region above $68 \mathrm{~m}$. The three sections with fitted lines represent the upper, middle and lower segments of the thermal maximum. A noticeable difference is observed in the slope of the upper rise section and convective section where a sharp step occurs in some years. This is probably a result of the small convective layer near $65 \mathrm{~m}$. 
mitigate the effects of the convective boundary on the energy estimates, only the deepest few points were used in estimating the slope. Values of fluxes and source depths from all years were averaged together, which provided a better approximation than using a single value. Table I contains a summary of the heat fluxes, line fits, energy source depths (segment intersections) and magnitudes for all years. It also includes the averaged energy values used in subsequent sections. The total energy required to maintain the temperature maximum was $0.162 \mathrm{~W} \mathrm{~m}^{-2}$ and the larger portion was generated by the upper source. The upper source was predicted to be $0.106 \mathrm{~W} \mathrm{~m}^{-2}$ at a depth of approximately $70.9 \mathrm{~m}$, while the lower source was predicted to be $0.056 \mathrm{~W} \mathrm{~m}^{-2}$ at a depth of approximately $80.2 \mathrm{~m}$.

\section{Chemical and biological heat model}

There are several possible metabolic pathways that could produce energy in this zone of the water column. Of these aerobic methane oxidation is the largest producer of heat because of its high energy yield and the high methane flux through the water column. As discussed above, the linear profile of methane from $80-99 \mathrm{~m}$ depth implies a methane flux of $\sim 1 \times 10^{-9} \mathrm{~mol} \mathrm{~m}^{-2} \mathrm{~s}^{-1}$ upward from lake bottom. If all of this methane reacted with oxygen to produce carbon dioxide and water, the resulting energy is $\sim 1 \times 10^{-3} \mathrm{~W} \mathrm{~m}^{-2}$, about $1 \%$ of the energy needed to maintain the temperature maximum.

\section{Radiative energy heat model}

The bulk of the radiative energy was lost in the upper water column prior to reaching the temperature maximum (Fig. 6). Assuming a 100\% conversion from radiative energy to heat, the net radiative flux into the diffusive zone below $70 \mathrm{~m}$, as estimated by the scaled measured PAR profile, was $0.18 \mathrm{~W} \mathrm{~m}^{-2}$. This was $111 \%$ of the radiative flux $\left(0.162 \mathrm{~W} \mathrm{~m}^{-2}\right)$ required to maintain the temperature maximum given the computed diffusive loss of heat (Fig. 5) and well within the uncertainties of the calculations. In addition, the structure of the energy generation profile (Fig. 6b) had two peaks occurring at $72.5 \mathrm{~m}$ and $78.5 \mathrm{~m}$ depth, which were similar to the estimated locations from the thermal analysis pointing to heating sources at $70.9 \mathrm{~m}$ and $80.2 \mathrm{~m}$ depth.

\section{Discussion}

Detailed temperature profiles of the anoxic zone span from February 1985 (Wand et al. 2006) to November 2016. Within the spacing of the measurements the structure of the deep temperature profiles are identical, placing a limit on any systematic changes in the level of the lake to $<1 \mathrm{~m}$ over this two-decade period. In comparison, the level of Lake Vanda increased by $15 \mathrm{~m}$ from 1965-2015 (Fig. 4 and Castendyk et al. 2016) or approximately $3 \mathrm{~m} \mathrm{dec}^{-1}$. Above $50 \mathrm{~m}$ depth in the anoxic trough, the lake is well mixed from convective currents that are driven by contact with the face of the Anuchin Glacier. This is evident in the uniform profiles above the sill that divides the anoxic trough from the main body at $50 \mathrm{~m}$ depth (Steel et al. 2015). There is a second mixed zone that sits between the thermocline $(50 \mathrm{~m})$ and chemocline $(68 \mathrm{~m})$. In this zone the temperature and density are higher than that of the main lake but the dissolved oxygen concentration is essentially the same. This suggests that the convective mixing in this zone can transport enough dissolved oxygen to maintain its concentration equal to the value in the upper layers of the lake. The mixing also maintains isothermal conditions, but apparently the mixing is not strong enough to keep the temperature equal to the temperature of the water in the upper layers of the lake, $\sim 0^{\circ} \mathrm{C}$ and the water is warmed to $4^{\circ} \mathrm{C}$. This is probably due to the stability of water at its density maximum, $4^{\circ} \mathrm{C}$, favouring this value of the temperature. There is no corresponding effect on the level of dissolved oxygen. However, just above the chemocline there is a small instability between $64 \mathrm{~m}$ and $69 \mathrm{~m}$ depth where density appears to decrease slightly $\left(0.005 \mathrm{~kg} \mathrm{~m}^{-3}\right)$. Stability through the profiles arises from an increase in salt concentrations, which offsets density changes from increasing temperature over the density maximum of water. In Antarctic lakes Vanda and Bonney, salts are the primary component to stability (Wilson \& Wellman 1962, Shirtcliffe \& Benseman 1964, Spigel et al. 2018). Though Lake Untersee has very low concentrations of salts compared to those systems, dissolved salts are also the stabilizing agent (table 2 in Wand et al. 2006 \& table 1 in Andersen et al. 2011).

From the shape of the temperature profile (Fig. 5) it is clear that the heating structure required to explain the thermal maximum is more complex than in other Antarctic lakes that also show temperature rises with depth. The energy flux of $0.162 \mathrm{~W} \mathrm{~m}^{-2}$ required to explain the temperature maxima $(71 \mathrm{~m})$ is $5-10$ times lower than estimated values for other Antarctic lakes, such as Vanda (Wilson \& Wellman 1962), Miers (Bell 1967), and Bonney (Shirtcliffe 1964). One possible explanation for this difference is the magnitude of the temperature anomaly, which in the case of Lake Untersee is only $1^{\circ} \mathrm{C}$ while the anomalies in other lakes are much larger. As discussed above, a single distributed source does not adequately approximate the observed profile. Instead, two thin layers at $70.9 \mathrm{~m}$ and $80.2 \mathrm{~m}$ depth that act as point sources of heat in the water column are required to explain the profile. In the remainder of the paper and in Table I these will be referred to as point layers. 

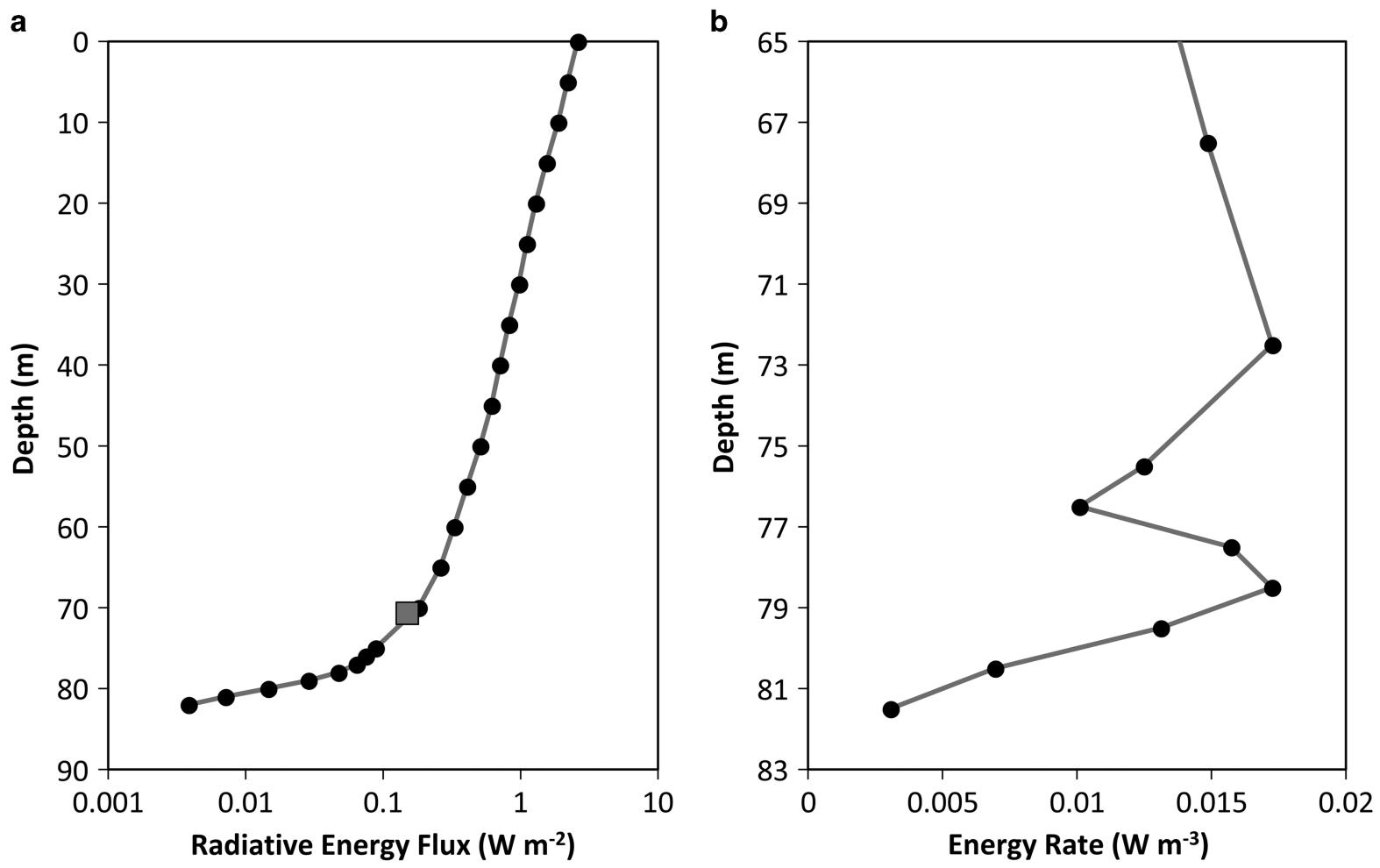

Fig. 6. a. Solar radiation in the anoxic trough scaled by setting the light level just below the ice to $2.6 \mathrm{~W}^{-2}$, the mean annual irradiance (Steele et al. 2015). The square indicates the energy to maintain the thermal rise in the anoxic trough. b. Heating from solar radiation calculated from the slope of the profile. Most of the absorption occurs in the upper portion of the water column. At $\sim 70 \mathrm{~m}$ the profile deviates indicating additional opacity. The heating profile has peaks at $72.5 \mathrm{~m}$ and $78.5 \mathrm{~m}$ which agree with the predicted values of 70.5 and $79.9 \mathrm{~m}$.

The thermal analysis provides boundaries and guidance for evaluating plausible energy sources to explain the temperature profile (Wand et al. 2006). The maximum heating from metabolic reactions (i.e. methane oxidation) is several orders of magnitude smaller than the energy required to cause the observed raise in temperature. Methane oxidation is the single largest chemical contributor to heating because of the high concentration of methane in the water column and a highenergy yield. Thus, one can conclude that chemical and biological reactions are not the primary heating source.

The dominant energy source is solar heating through the water column. In the case of Lake Untersee, the estimated radiative input of $0.18 \mathrm{~W} \mathrm{~m}^{-2}$ through the water column was $111 \%$ of the energy flux required to explain the temperature maxima. The discrepancy $(11 \%)$ between estimated radiative input values and required radiative input values is similar to other studies in Antarctic lakes (Wilson \& Wellman 1962, Shirtcliffe 1964) and falls within the $20 \%$ error that is commensurate with the methods used in this analysis. However, the absolute discrepancy in the case of Lake Untersee $\left(0.018 \mathrm{~W} \mathrm{~m}^{-2}\right)$ is 3-5 times smaller than the $0.066 \mathrm{~W} \mathrm{~m}^{-2}$ reported by Wilson \& Wellman (1962) and $0.106 \mathrm{~W} \mathrm{~m}^{-2}$ reported by Shirtcliffe (1964) for Lake Vanda.
Energy input peaks are predicted from the solar radiation profile at $72.5 \mathrm{~m}$ and $78.5 \mathrm{~m}$ depth (Fig. 6b), which are similar to the estimates of $70.9 \mathrm{~m}$ and $80.2 \mathrm{~m}$ from the thermal analysis. The location of the upper peak is in a section where sampling resolution was $5 \mathrm{~m}$ for most of the profiles, so there is a large error associated with the true location. The lower peak is within a section of $1 \mathrm{~m}$ sampling resolution but occurs within $2 \mathrm{~m}$ of the estimated location, which given the uncertainty in the data is in good agreement.

The upper temperature point layer would receive a higher solar radiation flux, and only a relatively small portion of that solar radiation flux would need to be converted into heat to explain the observed change in temperature. The chl $a$ profile from 2011 showed a distinct peak at the same location as the upper temperature peak (Fig. 4) and was similar to the profile of dissolved organic carbon reported by Wand et al. (2006). This suggests that there is a high density of phytoplankton at this depth, which is located at the chemocline/oxycline. However, photosynthesis alone is probably not capable of converting this radiative energy into heat, because the energy used by the phytoplankton in Antarctic lakes is only 3-8\% of the incoming radiative energy (Seaburg et al. 1983). Instead, it is more likely that 
Table 1. Summary of energy fluxes, line fits and energy sources*.

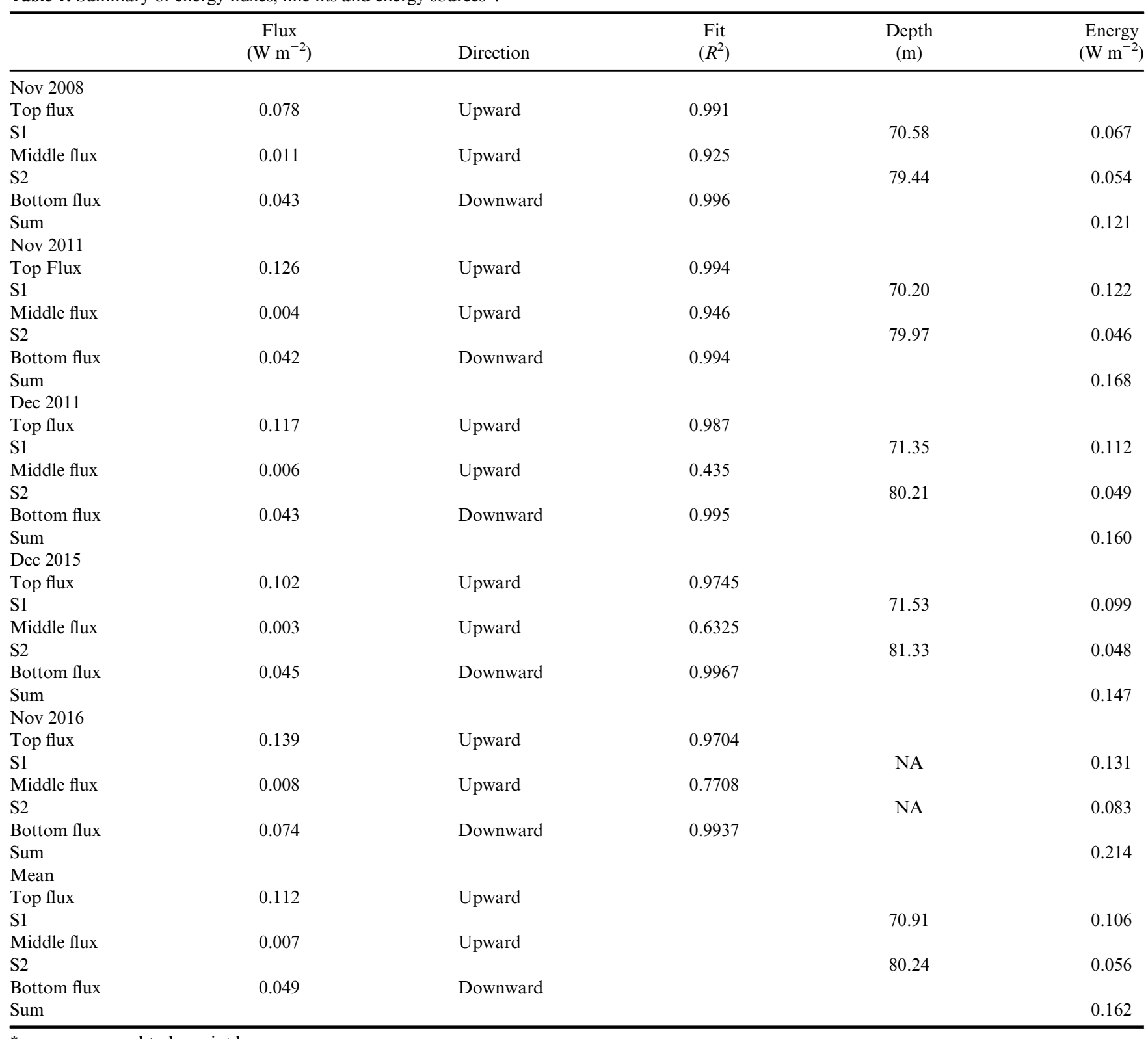

*sources assumed to be point layers

photosynthesis is a source of energy that supports the growth of phytoplankton and that the phytoplankton and the microbial community that it supports acts as a source of opacity in the water. A similar mechanism of heating is probably active in Lake Vanda (Wilson \& Wellman 1962, Vincent et al. 1998).

The lower thermal generation point layer would receive a solar radiation flux equivalent to $10 \%$ of the solar flux at the upper peak. Thus, the water column must be more opaque at the lower peak for a more efficient heat conversion. It is likely that this lower heat-absorbing layer is from particulate organic and/or inorganic matter and not from chl $a$, as it occurs at the depth where methane oxidation and sulfate production reach maximum values (Wand et al. 2006). Again, the depth spacing in our data makes precise determination of the location impossible, but it is plausible that there is a layer of chemotrophic microorganisms at this depth that are supported by chemical species in the water column. This microbial-rich layer and other associated organic molecules could act as a source of opacity to convert incoming radiative energy to heat (Markager \& Vincent 2000, Thrane et al. 2014). Interestingly, the depths of the upper and lower heat peaks coincide with the upper and lower boundaries of the suboxic zone defined by Wand et al. (2006). The top of this zone is the oxycline while the bottom is a transition to fully anoxic conditions. 
The timescales required to generate the observed thermal profile can be estimated by dividing the amount of energy required to heat the water column by the observed energy flux into the water column. The time required to heat the water column below the well mixed zone at $50 \mathrm{~m}$ depth to the bottom at $100 \mathrm{~m}$ from $0^{\circ} \mathrm{C}$ to the first temperature step $\left(4^{\circ} \mathrm{C}\right)$ by solar radiation $\left(0.45 \mathrm{~W} \mathrm{~m}^{-2}\right.$, as seen in Fig. 6$)$ is approximately 60 years. The time required to heat the water column at the second temperature step $\left(4-5^{\circ} \mathrm{C}\right)$ from $62-92 \mathrm{~m}$ from the predicted energy input $\left(0.16 \mathrm{~W} \mathrm{~m}^{-2}\right)$ is $\sim 14$ years. This timescale is shorter than the 25 -year time period for which the thermal rise has been observed suggesting that the heating mechanisms is active at the current time. The fact that it takes only 14 years to create a $1{ }^{\circ} \mathrm{C}$ rise in temperature is also noteworthy because it shows how quickly the structure of the anoxic trough could change should solar radiation at depth increase as a result from changes in climate or lake level. Changes in the deep thermal structure of this magnitude over $~ 80$-year timescales have been reported for Lake Vanda (Castendyk et al. 2016).

Lake Untersee may be a sensitive indicator ecosystem for climate change. Andersen et al. (2015) found that a $1^{\circ} \mathrm{C}$ rise in mean air temperature would result in meltwater flowing down the Anuchin Glacier leading to the formation of runoff channels on the glacier, moats around the lake, and the introduction of dissolved $\mathrm{CO}_{2}$ into the water column. This in turn would drive down $\mathrm{pH}$ leading to the precipitation of carbonates and silicates. Streamflow derived from glacial runoff would dramatically increase the load of fine sediments transported into the extremely transparent water column. In this regard, it is interesting to note that the thermal structure of the anaerobic basin may dramatically alter in response to changes in the radiation balance of the surface of the lake and the opacity of the upper water column. The profiles over 20 years provide a baseline record of long-term stability.

\section{Conclusion}

Lake Untersee has a thermal structure that is unusual among ice-covered Antarctic lakes, due to the geometry of the lake and the resultant formation of an anoxic trough. The main lake body and the larger basin are all well mixed, isothermal and uniformly saturated with dissolved oxygen. The anoxic conditions in the trough persist because of the deep yet narrow geometry, which shields the water from mixing currents. There are distinct zones in the water column of the anoxic trough. The upper zone $(0-50 \mathrm{~m})$ is part of the main lake body and connected by current-driven mixing. The zone from $50-68 \mathrm{~m}$ is slightly mixed and maintains a separation of the oxycline from the thermocline. The zone from $68 \mathrm{~m}$ to the bottom at $100 \mathrm{~m}$ is purely diffusive and has an unexpected thermal temperature rise of $1^{\circ} \mathrm{C}$. The structure of the profile in this region is best reproduced with two discrete sources acting at different depths. The top source coincides with a photosynthetic layer just at the oxycline while the second source overlays the depth where peak methane oxidation and sulfate reduction rates occur. While metabolic reactions could account for only $1 \%$ of the required energy, solar radiation can account for $111 \%$ of the required energy. Thus, heating of the anoxic basin is more likely due to these microbial populations acting as sources of opacity, which converts solar radiation into heat.

The stability of the temperature maximum is maintained by dissolved solids in the water column, which are most likely dissolved salts in low concentrations. The thermal rise in Lake Untersee is different from those found in Lake Vanda and Lake Bonney by being deeper, smaller in the maximum temperature, but similar in that stability is maintained by dissolved salts.

The combination of physical setting, a glacier wall, which induces mixing, topography of the anoxic trough that shields the basin to the mixing, and the depth of the anoxic trough, make Lake Untersee unusual among Antarctic lakes. These features result in a diffusion zone and the formation of an oxycline and chemocline. Biological entities respond to the availability of oxidants and reductants at the chemocline by creating biomass. This leads to opacity in the water, which then absorbs solar flux creating a thermal maximum.

Our analysis shows that the structure of the thermal profile depends on the penetration of surface radiation. If future climate change results in a change in solar radiation this will directly affect the thermal profile.

\section{Acknowledgements}

Primary support for this research was provided by the Tawani Foundation, the Trottier Family Foundation, the Arctic and Antarctic Research Institute/Russian Antarctic Expedition's Subprogram "Study and Research of the Antarctic" of the Federal Target Program "World Ocean", and NASA's Astrobiology Program. Logistics support was provided by Antarctic Logistics Centre International (ALCI), Cape Town, South Africa. We are grateful to Colonel (IL) J. N. Pritzker, IL ARNG (retired), Lorne Trottier, and fellow field team members for their support during the expedition. The authors also thank Robert Spigel and a second anonymous reviewer for constructive comments on the text.

\section{Author contributions}

JB developed the conceptual model of heating and density stability. All authors contributed to the writing and 
analysis. Field work was conducted by DTA, CPM, AD, IH and YT.

\section{Supplemental data}

The raw data used in this manuscript are freely available as an excel file at https://doi.org/10.1017/ S0954102018000354. The file includes data from various Lake Untersee column profiles for temperature conductivity, $\mathrm{pH}$, Dissolved oxygen and light; and data used for water density and thermal flux calculations.

\section{References}

Andersen, D.T., McKay, C.P. \& Lagun, V. 2015. Climate conditions at perennially ice-covered Lake Untersee, East Antarctica. Journal of Applied Meteorology and Climatology, 54, 1393-1412.

Andersen, D.T., Sumner, D.Y., Hawes, I., Webster-Brown, J. \& McKaY, C.P. 2011. Discovery of large conical stromatolites in Lake Untersee, Antarctica. Geobiology, 9, 280-293.

Bell, R.A.I. 1967. Lake Miers, South Victoria Land, Antarctica. New Zealand Journal of Geology and Geophysics, 10, 540-556.

Boehrer, B., Herzsprung, P. \& Millero, F.J. 2010. Calculating density of water in geochemical lake stratification models. Limnology and Oceanography: Methods, 8, 567-574.

Castendyk, D.N., Obryk, M.K., Leidman, S.Z., Gooseff, M. \& Hawes, I. 2016. Lake Vanda: a sentinel for climate change in the McMurdo Sound region of Antarctica. Global and Planetary Change, 144, 213-227.

Chen, C.-T. \& Millero, F.J. 1977. The use and misuse of pure water PVT properties for lake waters. Nature, 266, 707-708.

Chen, C.-T. \& Millero, F.J. 1986. Precise thermodynamic properties for natural waters covering only the limnological range. Limnology and Oceanography, 31, 657-662.

FofonofF, N.P. \& Millard JR, R.C. 1983. Algorithms for computation of fundamental properties of seawater. In UNESCO Technical Papers in Marine Science 44. Paris, France: UNESCO, 53.

Heitz, W.L. \& Westwater, J.W. 1971. Critical Rayleigh numbers for natural convection of water confined in square cells with L/D from 0.5 to 8. Journal of Heat Transfer, 93, 188-195.

Hoare, R.A., Popplewell, K.B., House, D.A., Henderson, R.A., Prebble, W.M. \& Wilson, A.T. 1964. Lake Bonney, Taylor Valley, Antarctica: a natural solar energy trap. Nature, 202, 886-888.

Hoare, R.A., Popplewell, K.B., House, D.A., Henderson, R.A., Prebble, W.M. \& Wilson, A.T. 1965. Solar heating of Lake Fryxell, a permanently ice-covered Antarctic lake. Journal of Geophysical Research, 70, 1555-1558.

LewIS, E. 1980. The practical salinity scale 1978 and its antecedents. IEEE Journal of Oceanic Engineering, 5, 3-8.

Loopmann, A., Kaup, E., Klokov, V, Simonov, I. \& Haendel, D. 1988. The bathymetry of some lakes of the Antarctic oases Schirmacher and Untersee. In MARTiN, J., ed. Limnological studies in Queen Maud Land (East Antarctica). Tallinn: Eesti NSV Teaduste Akadeemia, 6-14.

MARKAGER, S. \& VINCENT, W.F. 2000. Spectral light attenuation and the absorption of UV and blue light in natural waters. Limnology and Oceanography, 3, 642-650.

McKay, C.P., Clow, G.D., Andersen, D.T. \& Wharton, R.A. 1994. Light transmission and reflection in perennially ice-covered Lake Hoare, Antarctica. Journal of Geophysical Research - Oceans, 99, 20 427-20 444 .
Millero, F.J. \& Poisson, A. 1981. International one-atmosphere equation of state of seawater. Deep Sea Research I: Oceanographic Research Papers, 28, 625-629.

Obryk, M.K., Doran, P.T., Hicks, J.A., McKay, C.P. \& Priscu, J.C. 2016. Modeling the thickness of perennial ice covers on stratified lakes of the Taylor Valley, Antarctica. Journal of Glaciology, 62, 825-834.

PIRT, S.J. 1978. Aerobic and anaerobic microbial digestion in waste reclamation. Journal of Applied Chemistry Biotechnology, 28, 232-236.

Ramires, M.L.V., Nieto De Castro, C.A., Nagasaka, Y., Nagashima, A., Assael, M.J. \& WaKeham, W.A. 1995. Standard reference data for the thermal conductivity of water. Journal of Physical and Chemical Reference Data, 24, 1377-1381.

Schwabe, S. \& Herbert, R.A. 2004. Black holes of the Bahamas: what they are and why they are black. Quaternary International, 121, 3-11.

Seaburg, K.G., Kaspar, M. \& Parker, B.C. 1983. Photosynthetic quantum efficiencies of phytoplankton from perennially ice-covered Antarctic lakes. Journal of Phycology, 19, 446-452.

SHIRTCLIFFe, T.G.L. 1964. Lake Bonney, Antarctica: cause of the elevated temperatures. Journal of Geophysical Research, 69, 5257-5268.

Shirtcliffe, T.G.L. \& Benseman, R.F. 1964. A sun-heated Antarctic lake. Journal of Geophysical Research, 69, 3355-3359.

Spigel, R.H. \& Priscu, J.C. 1996. Evolution of temperature and salt structure of Lake Bonney, a chemically stratified Antarctic lake. Hydrobiologia, 321, 177-190.

Spigel, R.H. \& Priscu, J.C. 1998. Physical limnology of the McMurdo Dry Valleys lakes. Antarctic Research Series, 72, 153-187.

Spigel, R.H., Priscu, J.C., Obryk, M.K., Stone, W. \& Doran, P.T. 2018. The physical limnology of a permanently ice-covered and chemically stratified Antarctic lake using high resolution spatial data from an autonomous underwater vehicle. Limnology and Oceanography, 63, 1234-1252.

Steel, H.C.B., McKay, C.P. \& Andersen, D.T. 2015. Modeling circulation and seasonal fluctuations in perennially ice-covered and ice-walled Lake Untersee, Antarctica. Limnology and Oceanography, 60, 1139-1155.

Thrane, J.-E., Hessen, D.O. \& Andersen, T. 2014. The absorption of light in lakes: negative impact of dissolved organic carbon on primary productivity. Ecosystems, 17, 1040-1052.

Vincent, W.F., Rae, R., Laurion, I., Howard-Williams, C. \& Priscu, J.C. 1998. Transparency of Antarctic ice-covered lakes to solar UV radiation. Limnology and Oceanography, 43, 618-624.

Wand, U., Samarkin, V., Nitzsche, H. \& Hubberten, H. 2006. Biogeochemistry of methane in the permanently ice-covered Lake Untersee, central Dronning Maud Land, East Antarctica. Limnology and Oceanography, 51, 1180-1194.

Wand, U., Schwab, M., Samarkin, W.A. \& Schachtschneidek, D. 1996. Sedimentgeologische Arbeiten während der Expedition Schirmacheroase 1994/95 des AWI, Forschungsstelle Potsdam. Berichte zur Polurforschung, 215, 73-122.

Wand, U., Schwarz, G., Brüggemann, E. \& Bräuer, K. 1997. Evidence for physical and chemical stratification in Lake Untersee (central Dronning Maud Land, East Antarctica). Antarctic Science, 9, 43-45.

Warren, S.G. \& Brandt, R.E. 2008. Optical constants of ice from the ultraviolet to the microwave: a revised compilation. Journal of Geophysical Research - Atmospheres, 113, 10.1029/2007JD009744.

WEAST, R.C. 1976. CRC handbook of chemistry and physics, 57th ed. Cleveland, OH: CRC Press.

Wilson, A.T. \& Wellman, H.W. 1962. Lake Vanda: an Antarctic lake: Lake Vanda as a solar energy trap. Nature, 196, 1171-1173.

Yaws, C.L. 2009. Transport Properties of Chemicals and Hydrocarbons, 1st ed. Norwich, NY: William Andrew, 600 pp. 